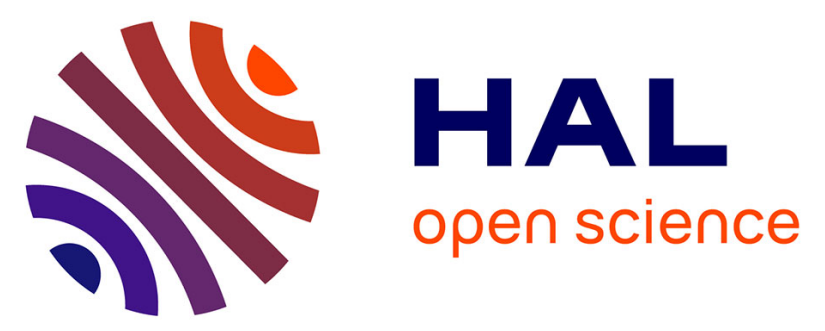

\title{
Towards a Collaborative and Open Supply Chain Management Operating Services Platform
}

Matthieu Lauras, Raphaël Oger, Jiayao Li, Benoit Montreuil, Markus Kohl, Andreas Habl, Julien Lesbegueries

\section{- To cite this version:}

Matthieu Lauras, Raphaël Oger, Jiayao Li, Benoit Montreuil, Markus Kohl, et al.. Towards a Collaborative and Open Supply Chain Management Operating Services Platform. 22nd Working Conference on Virtual Enterprises (PRO-VE 2021), Nov 2021, Saint-Etienne, France. pp.611-622, 10.1007/9783-030-85969-5_57. emse-03346653

\section{HAL Id: emse-03346653}

\section{https://hal-emse.ccsd.cnrs.fr/emse-03346653}

Submitted on 25 Nov 2021

HAL is a multi-disciplinary open access archive for the deposit and dissemination of scientific research documents, whether they are published or not. The documents may come from teaching and research institutions in France or abroad, or from public or private research centers.
L'archive ouverte pluridisciplinaire HAL, est destinée au dépôt et à la diffusion de documents scientifiques de niveau recherche, publiés ou non, émanant des établissements d'enseignement et de recherche français ou étrangers, des laboratoires publics ou privés. 


\title{
Towards a Collaborative and Open Supply Chain Management Operating Services Platform
}

\author{
Matthieu Lauras ${ }^{1,2}$, Raphaël Oger ${ }^{1}$, Jiayao Li $^{1}$, Benoit Montreuil ${ }^{2}$, \\ Markus Kohl ${ }^{3}$, Andreas $\mathrm{Habl}^{3}$ and Julien Lesbegueries ${ }^{1}$ \\ ${ }^{1}$ Centre Génie Industriel, IMT Mines Albi, University of Toulouse, Albi, France \\ \{matthieu.lauras, raphael.oger, jiayao.li, julien.lesbegueries\}@mines-albi.fr \\ ${ }^{2}$ Physical Internet Center, ISYE School, Georgia Institute of Technology, Atlanta, U.S.A \\ \{benoit.montreuil\}@isye.gatech.edu \\ ${ }^{3}$ Chair of Materials Handling, Material Flow, Logistics, Technical University of Munich, \\ Munich, Germany \\ \{makus.kohl, andreas.habl\}@tum.de
}

\begin{abstract}
Supply Chain (SC) uncertainty perspectives must now be translated into practice. $\mathrm{SC}$ entities must accept crises and catastrophes as normal situations and increase significantly their culture of SC risk management. They should adapt their decision-support systems to be able considering disruptions as regular inputs, whether small, large or huge. Collaboration should not be limited to few entities of a SC, but to the whole SC. Concrete tools allowing entities to share vital information to give visibility, ensure synchronization of the material flows, align management of emergencies and use of critical resources must be developed and used. That is the purpose of this paper. Practically, a framework for SC risk and opportunity management and a Collaborative and Open Supply Chain Management Operating Services (COSMOS) platform are presented. An illustrative case is developed to highlight the potential benefits of the proposal on one service example.
\end{abstract}

Keywords: Supply chain management, Collaborative information systems, Decision support systems, Uncertainty, Risk management.

\section{Introduction}

Current Supply Chains (SCs) have never been so vulnerable to unexpected disruptive events along with the increased complexity of highly dynamic business environment. Recently, as COVID-19 pandemic reveals, an unprecedented disruption in supply and demand is caused that affects numerous both global and local availability of SC activities [1]. It's a fact that today's SCs have demonstrated during this crisis, a poor ability to make efficient and responsive decisions to supply on time and in-full vital, but also basic, necessities. As illustrated in [2], the pandemic necessitates SCs and tools coping with enormous uncertainties as a new normal, but the knowledge of an effective and efficient way of recovering from the disturbance is still quite limited. Certainly, COVID-19 amplifies the needs for agility and resilience for SCs. 
With a long-term view, effective decision-making has a significant impact on resilient capabilities of collaborative networks [3]. However, such a situation has led to great pressure on stakeholders to make prudential decisions, especially in the face of multitude uncertainties and decision options. Developing a Decision Support System (DSS) is obviously a good way to provide a better visibility and understanding of available options, which enables an optimal decision-making for SCs [4]. But most of current decision-support tools fail to act beyond legacy SC management dogmas and practices [5]. So far, neither in research nor in practices there exist effective and efficient tools that help with overcoming the stated challenges on a long-term perspective, due to a lack of methodological foundation and necessary requirements.

Consequently, it is pivotal to develop suitable tools for both researchers and practitioners that provide reliable guidance for decisions in order to create and maintain stable SCs to support company recovery. What is more, it is crucial that those tools not only recreate economic growth, but also that they support a sustainable long-term business strategy and decision processes under the new circumstances by assuring SC flexibility and resilience in a way that suits the new normal.

In this context, the paper presents an innovative Collaborative and Open Supply chain Management Operating Services (COSMOS) platform that is dedicated to management of uncertainties, variabilities and disruptions in SCs. The COSMOS platform aims to provide actors in the $\mathrm{SC}$ with a range of tools that could help them to better manage the huge variabilities they may face in the months and years ahead. In order to achieve the objective, two building blocks are designed and developed, including a software portfolio with open online software services and a knowledge hub with a set of documents and methodological tools relevant for managing the new normal. The remainder of the paper is organized as follows. A brief review of the related works is summarized before introducing the core proposal of the COSMOS platform. Then, an illustrative showcase for one service example embedded in the platform are presented before concluding and opening avenues for future research.

\section{Background and Related Work}

As the COVID-19 crisis reveals, uncertainty-driven SC management is already the new normal. Regarding the definition of SC uncertainty, as given by [6], the term is used to depict decision-making situations that lacks information to accurately predict the effect of SC behaviors or simply lacks appropriate response solutions. Given that SC uncertainty and risk are usually utilized indiscriminately in the literature of SC management, some authors suggest that SC risk mainly reflects negative impacts, while uncertainty may both have positive and negative impacts on SC performance [7]. The article also holds this vision of SC uncertainty that the term can be used to contain the issues of risk to some extent.

During the past decades, many uncertainty-driven SC management techniques have been developed for dealing with disruptions and instabilities. For instance, simulation has been widely used in SC risk modeling, which contributes to the understanding of the impact of interactive factors from a systematic perspective [8]. Besides, stochastic programming and multi-criteria decision making have been effectively utilized to 
analyze or assess SC uncertainties. Although various approaches for uncertainty-driven SC management have been widely discussed within the literature, they are mainly dedicated to risk identification, assessment, and modeling. It is worth to mention that there is a limited formal solution on how to support decision-making processes from a long-term practical perspective for managing uncertainties.

Regarding the current DSS used for SC management, numerous technologies and systems have been set up for SC collaboration, such as EDI (Electronic Data Interchange), CPFR (Collaborative Planning, Forecasting and Replenishment) or VMI (Vendor Managed Inventory) for instance [9]. With regard to the need of SC planning, it relates to a series of forward-looking decisions in terms of coordinating information from supplier to customer, optimizing product delivery and service. The associated systems include MRP (Material Requirements Planning), MRPII (Manufacturing Requirements Planning, ERP (Enterprise Resource Planning) or APS (Advanced Planning and Scheduling).

To sum up, without any doubt, the development of the above-mentioned tools has been conductive to satisfying the needs of business in the context of nominal SCs. However, they are now obsolete as they have been designed to optimize performance in a stable and deterministic world. Even though many studies point out the importance of uncertainty-driven SC management in the current complex and dynamic SC environment; few of DSS in the literature can provide the decision-makers with sound solutions for the purpose of managing uncertainties. Moreover, opportunity-driven SC management will soon be the new normal. Since SCs have become more flexible and open, as presented in [10], the new state "hyperconnectivity" may bring many available opportunities for SC stakeholders. Consequently, the deep insight and reliable guidance for seizing opportunities will be clearly needed, while neither in research nor in practices is unable to support the ambition.

\section{Proposal}

In order to solve the problem statement previously described, we develop in this section our core proposal composed of two main components. First, a theoretical framework dedicated to the management of risks and opportunities in SC Management context is developed. Second, considering the previous framework, a Collaborative and Open Supply chain Management Operating Services (COSMOS) platform is presented.

\subsection{COSMOS Theoretical Framework}

Uncertainty management relates definitively to the management of risks and opportunities, which might be past, present or future ones. In we refer to the ISO 31000 , risk management process could be defined as formulated by [11] and exposed on Fig. 1. This process starts with the identification of disruption trigger event(s) (risks or opportunities in our context) and moves to the criticality assessment (defined as a combination of occurrence probability and impact potentiality). Then, decision-makers have to imagine a set of potential solutions or options allowing to avoid or limit the risk 
incidence, or to catch potential opportunities. All these options must be evaluated in terms of benefits and costs (accessibility) to select the most appropriate one. Finally, through a usual risk management perspective, the most well-balanced solution might be chosen, implemented and followed along the time.

If this approach has demonstrated some benefits in the past, it seems a bit obsolete regarding the new normal described in the previous sections of this paper. Notably, this risk and opportunity management lifecycle should now be focused not only the assets as it is usually the case but also on the business processes which are used to manage and execute the system under study. The new risk and opportunity management status must include its self-ability to make a situation better or worse. In addition, the considered trigger disruption events should be past, live and future to better manage the expected risk and opportunity management capabilities. As a consequence, the set of actionable options and creative solutions to manage risks and opportunities should be able simultaneously to:

- learn from past to avoid reproducing previous mistakes and errors: this step should consist in understanding bad behaviors and decisions regarding past risks or opportunities. This should allow defining efficient mitigation plans based on past data gathered from historical database.

- react live to reduce bad impacts of an ongoing situation: this step should consist in reacting on-the-fly to some real-time data gathered from legacy systems, opendata sources, IoT devices, etc. This should allow defining some alleviating plans, not to avoid risks but to reduce their immediate impacts or at the opposite to benefit from short-term unexpected opportunities.

- proact ahead to prevent potential short-term issues: this step should consist in assuming (through simulation techniques for instance) what should be the status of the SC in the near future according to the existing situation and to a set of challenged assumptions. This should allow designing some sidestep plans able to avoid future disruptions or at least to reduce their impact significantly. Same approach might also be used to take advantages of some in-coming situations.

- prepare future to secure long-term perspectives regarding large set of scenarios: this step should consist in predicting a set of potential futures regarding ongoing or potential demand, supply or internal variabilities in order to support a large, qualitative and quantitative "what-if" perspective. This should allow defining dynamic, wide and effective contingency plans.

This new vision of the risk management lifecycle might be formulated as on Fig. 2. From this, we suggest developing a dedicated platform able to receive and expose concrete technical solutions able to support parts of the functionalities presented in the $\mathrm{SC}$ risk and opportunity management framework. This platform is presented in the following section. 
Towards a Collaborative \& Open Supply chain Management Operating Services Platform 595

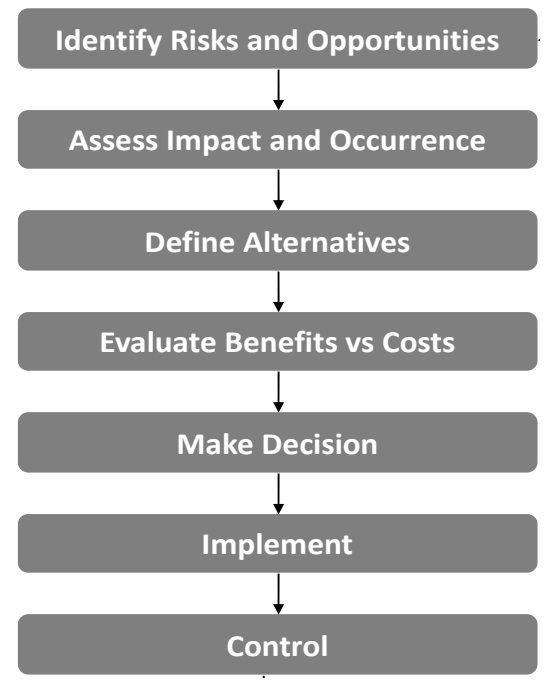

Fig. 1. Risk and opportunity management process [11]

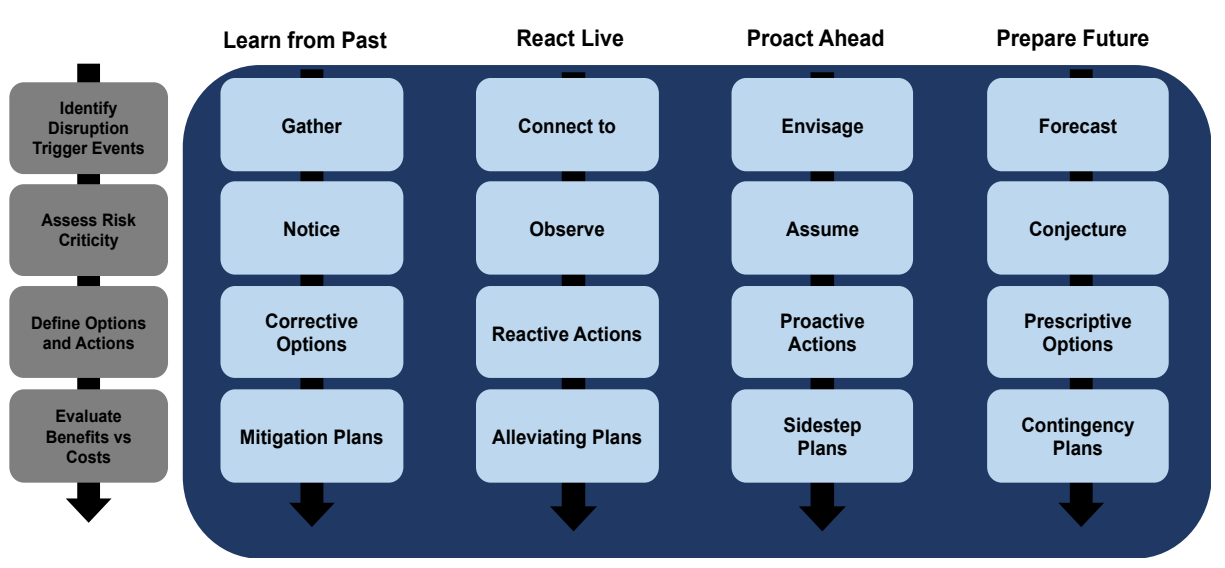

Fig. 2. A framework for SC risk and opportunity management

\subsection{COSMOS Platform}

\section{a) Big picture}

The objective of the COSMOS platform is to provide SC practitioners and scholars with openly accessible resources they can use to foster new ideas for improving and rethinking their SC management practices and knowledge. 
The COSMOS platform is composed of two building blocks:

- First, a software portfolio to provide open online software services.

- Second, a knowledge hub to provide a structured knowledge that can be used to better understand the $\mathrm{SC}$ new normal and its stakes.

From the business point of view, both building blocks are designed according to the proposed framework for organizing SCRM practices (Fig. 3). At this stage, most of the research efforts have been focused on the software portfolio, which is the focal point of the remaining of this paper.

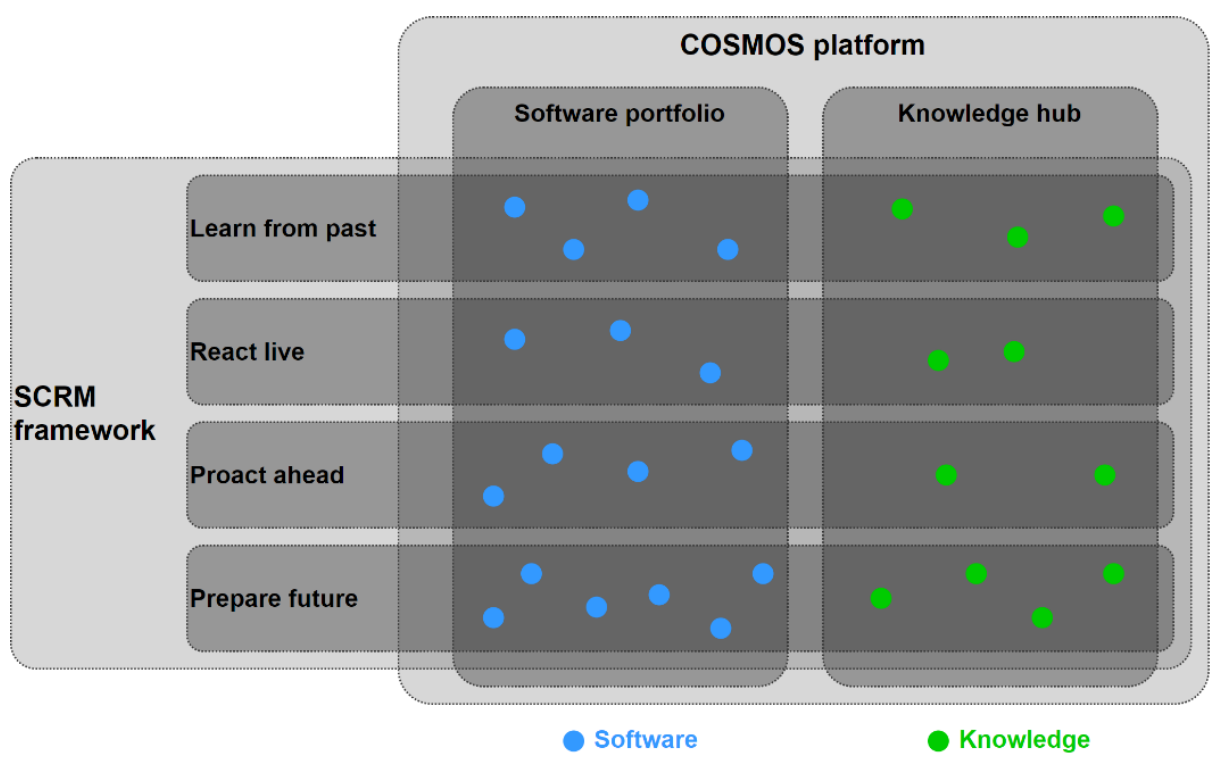

Fig. 3. COSMOS platform big picture

\section{b) Software portfolio}

Research projects in SC management regularly result in the development of software prototypes. Getting the knowledge and access to these prototypes could be a huge help to practitioners and scholars for fostering new ideas for improving and rethinking their $\mathrm{SC}$ management practices. However, these prototypes are not often easily accessible to a large panel of practitioners and scholars. Sometimes they do not even have graphical user interfaces. Therefore, the software portfolio has been designed with the objective of making these prototypes, resulting from research projects, openly accessible.

With that objective in mind, the software portfolio has been developed as a cloudbased platform accessible at the following URL: https://cosmos-portal.minesalbi.fr/portal/. Its architecture, from both the user and technical points of view, is illustrated in

Fig. 4.

From the user point of view, it is composed of the following two components: first, a homepage organizing the software prototypes according to the SCRM framework introduced in the previous subsection. This homepage provides information about the 
prototypes as well as links towards their web interface. Second, for each prototype, a web interface to use it. From the technical point of view, the web interfaces are divided in two categories. First, the internally hosted one, mainly used for prototypes that did not had web interfaces. Second, the externally hosted one, for prototypes that already had web interfaces. Then, each internally hosted software web interface relies on the use of software portfolio services, including a single sign-on service as well as a software services proxy. The latter enables web interfaces to use software services by calling the corresponding REST APIs.

A first selection of software to be included in the software portfolio homepage has been made. At this moment, the ones that appear are resulting from research projects undertaken by IMT Mines Albi and some of its partners. For example, the "SC mapper" and "advanced sales and operations planner" are resulting from a research project undertaken by [12], [13]. Another example is the "collaborative plans manager" resulting from a research project undertaken by [14]. Most of these software prototypes were not thought to be available online, therefore an effort is made to create web interfaces so they can be used on the COSMOS platform. Their integration is at different stages, so all currently displayed ones are not accessible yet.

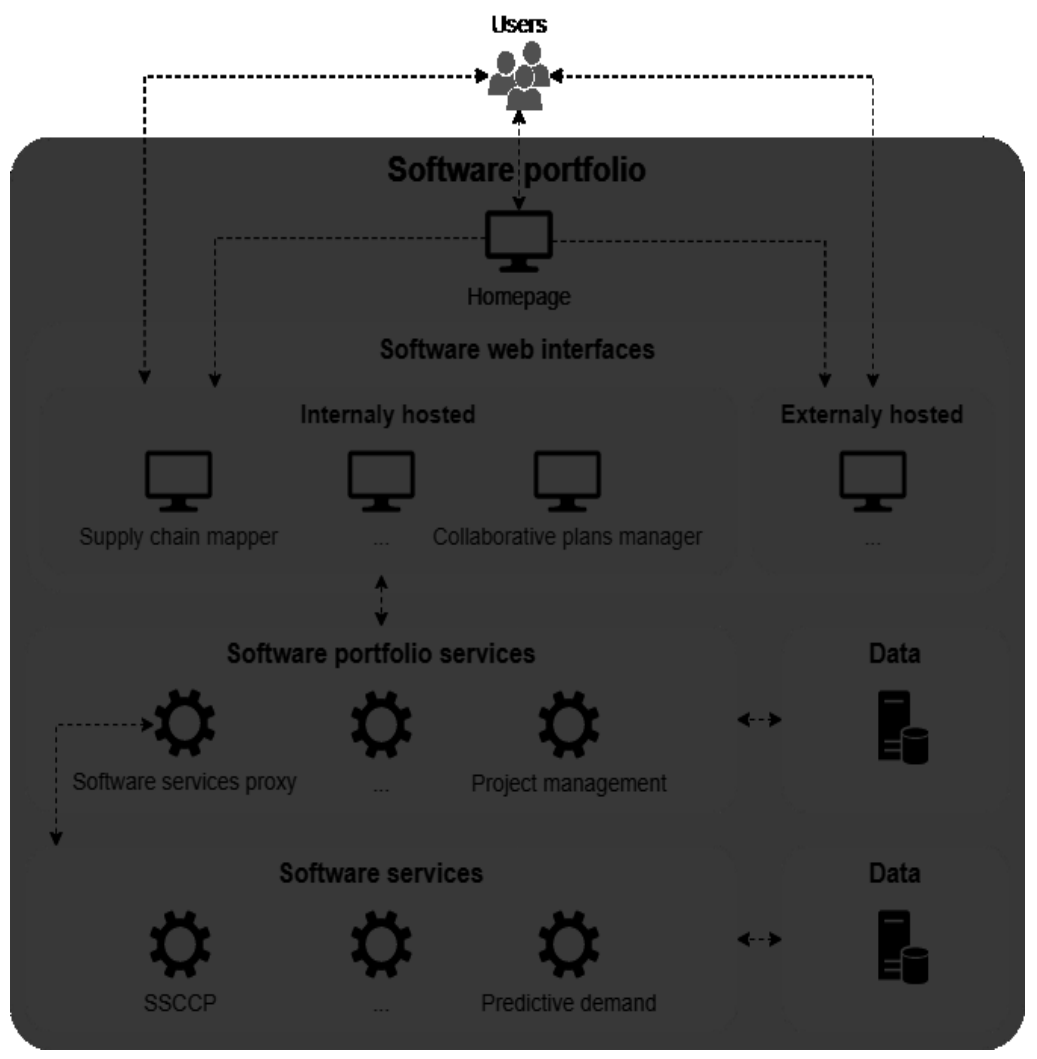

Fig. 4. Software portfolio architecture principles 


\section{Example of Service}

For the purpose of illustrating the use of software services of COSMOS platform, a simple showcase is designed in a scenario of pharmaceutical supply chain. The case concerns the production and distribution activity of a pharmaceutical product named as "Magic Capsule", as shown in Fig. 5, several stakeholders involve in the considered SC network.

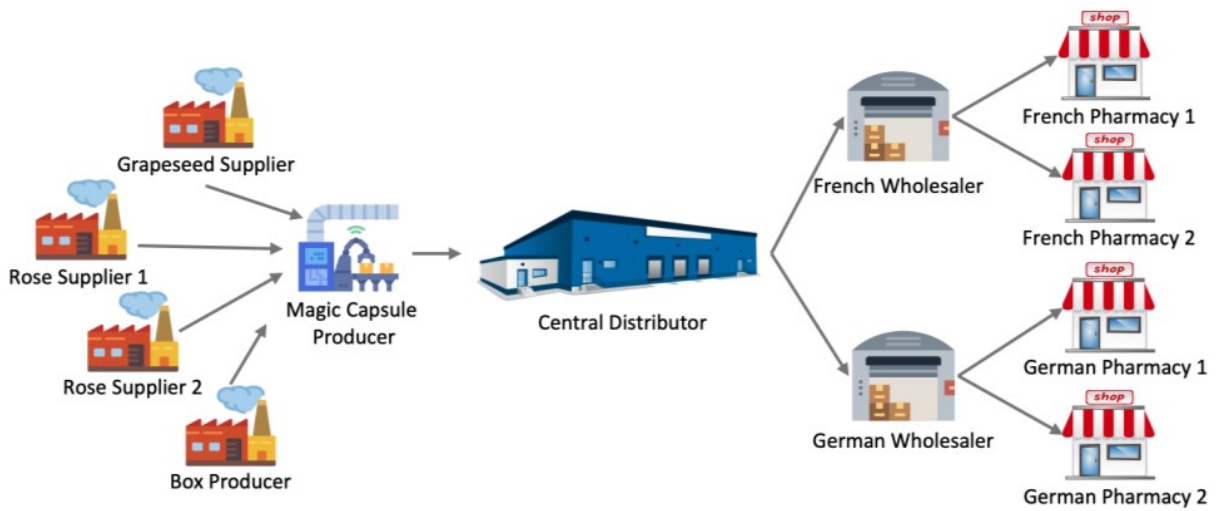

Fig. 5. The SC network of the "Magic Capsule" showcase

Generally speaking, the abilities of these stakeholders and their relationships can be described as follows:

- Two main raw materials (grapeseed and rose) are needed to produce the magic capsules, which are respectively provided by a grapeseed supplier and two rose suppliers.

- When the production of magic capsule is finished, those ones will be packed into two categories of products: box of 10 capsules and box of 100 capsules. The boxes are provided by a box producer.

- A central distributor is in charge of distributing the final products into a French wholesaler and a German wholesaler.

- The wholesalers implement the delivery to the corresponding country of two pharmacies.

According to the stated showcase, various software services can be instantiated to show the capabilities of the COSMOS platform. For example, "SC mapper", one of applications that concerns automated discovery of a SC map containing all possible $\mathrm{SC}$ options, which is based on an algorithm using information of SC stakeholders' capabilities referenced in a database. Fig. 6 shows the use of it with "Magic Capsule" showcase. A potential SC map can be deduced by importing a set of company-specific configuration files. The result map is able to help companies to identify SC alternatives and then to support SC design decisions. What is more, it also enables other software to take advantage of this SC map for additional decision-support features. 


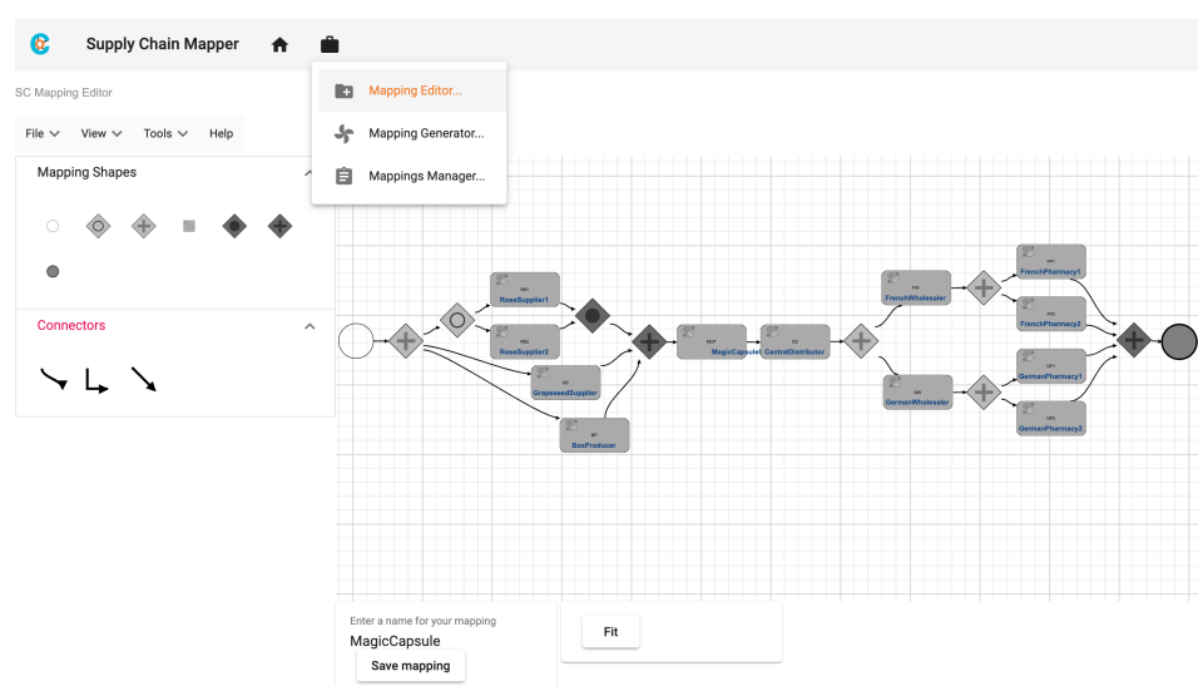

Fig. 6. The use of "SC mapper" with "Magic Capsule" showcase

\section{Conclusion and Future Works}

The first two sections of this paper have highlighted that SCs are dealing with a highly uncertain, opportunistic, and dynamic environment that challenges their ability to maintain their performance at satisfying levels. Companies driving these SCs lack knowledge, tools, and processes to efficiently make effective decisions in this context. As an answer to these difficulties faced by SC stakeholders, this paper makes two proposals in the third section that are then illustrated in the fourth section: first, a framework for SC risk and opportunity management that structures SCRM activities according to both a risk management lifecycle dimension and a temporality dimension (Fig. 2). Second, a platform dedicated to providing SC practitioners and scholars with openly accessible resources they can use to enhance their SC management practices and knowledge. This platform, called Collaborative and Open SC Management Operating Services (COSMOS), is organized according to the proposed SCRM framework, and composed of two building blocks: a software portfolio and a knowledge hub (Fig. 3). Finally, this paper fosters several avenues for future research. First, the consolidation of the COSMOS portal by making all already identified software prototypes accessible, intensifying the efforts for developing the knowledge portfolio, and enhancing the user experience so it can really become a platform that fosters new ideas for improving and rethinking SC management practices. A second avenue for future research is about identifying additional existing solutions that would be relevant to highlight according to the proposed SCRM framework. A third and broader one is about structuring current SC management challenges and identifying the ones that require research and development for designing new technological solutions to overcome these challenges. 
Acknowledgments. This research project has been partially funded by the GermanFrench Academy for the Industry of the Future (GFA) in the context of the call "Resilience and Sustainability for the Industry of the Future".

\section{References}

1. Ivanov, D.: Predicting the impacts of epidemic outbreaks on global supply chains: A simulation-based analysis on the coronavirus outbreak (COVID-19/SARS-CoV-2) case. Transportation Research Part E: Logistics and Transportation Review. 136, 101922 (2020).

2. El Baz, J., Ruel, S.: Can supply chain risk management practices mitigate the disruption impacts on supply chains' resilience and robustness? Evidence from an empirical survey in a COVID-19 outbreak era. International Journal of Production Economics. 233, 107972 (2021).

3. Singh, R.K., Modgil, S., Acharya, P.: Assessment of Supply Chain Flexibility Using System Dynamics Modeling. Glob J Flex Syst Manag. 20, 39-63 (2019).

4. Wang, X., Wong, T.N., Fan, Z.-P.: Ontology-based supply chain decision support for steel manufacturers in China. Expert Systems with Applications. 40, 7519-7533 (2013).

5. Pires Ribeiro, J., Barbosa-Povoa, A.: Supply Chain Resilience: Definitions and quantitative modelling approaches - A literature review. Computers \& Industrial Engineering. 115, 109-122 (2018).

6. van der Vorst, J.G.A.J., Beulens, A.J.M.: Identifying sources of uncertainty to generate supply chain redesign strategies. International Journal of Physical Distribution \& Logistics Management. 32, 409-430 (2002).

7. Simangunsong, E., Hendry, L.C., Stevenson, M.: Supply-chain uncertainty: a review and theoretical foundation for future research. International Journal of Production Research. 50, 4493-4523 (2012).

8. Ghadge, A., Dani, S., Kalawsky, R.: Supply chain risk management: present and future scope. Int. J. Logist. Manag. 23, 313-339 (2012).

9. McCarthy, T.M., Golicic, S.L.: Implementing collaborative forecasting to improve supply chain performance. International Journal of Physical Distribution \& Logistics Management. 32, 431-454 (2002).

10. Montreuil, B.: The Physical Internet: A Conceptual Journey, Keynote Presentation. 2nd International Physical Internet Conference (IPIC). Paris, France (2015).

11. Ben Taleb, R., Dahan, M., Montarnal, A., Lauras, M., Miclo, R.: Toward an Innvative Riskand Opportunity- Oriented System for SMEs' Decision-Makers. Presented at the Conférence Internationale en Génie Industrie QUALITA. Grenoble, France (2021).

12. Oger, R., Lauras, M., Montreuil, B., Benaben, F.: A decision support system for strategic supply chain capacity planning under uncertainty: conceptual framework and experiment. Enterprise Information Systems. 0, 1-45 (2020).

13. Oger, R., Benaben, F., Lauras, M., Montreuil, B.: Making Strategic Supply Chain Capacity Planning more Dynamic to cope with Hyperconnected and Uncertain Environments. In: Proceedings of the 54th Hawaii International Conference on System Sciences, pp. 2057. Hawaii (2021).

14. Tiss, S., Lamothe, J., Thierry, C.: Collaborative Supply Chain Distribution Planning under uncertainty. In: ILS 2020 - 8th International Conference on Information Systems, Logistics and Supply Chain, pp. 260-267. Austin, United States (2020). 